\title{
Congenital Hypogonadotropic Hypogonadism
}

National Cancer Institute

\section{Source}

National Cancer Institute. Congenital Hypogonadotropic Hypogonadism. NCI Thesaurus.

Code C120162.

Insufficient production of estrogen or testosterone in the ovaries or testes due to decreased secretion of gonadotropins as a result of pituitary or hypothalamus gland dysfunction that is present at birth. 